\title{
Hepatitis C virus infection in Canada's First Nations people: A growing problem
}

\author{
Matthew D Sadler MD, Samuel S Lee MD FRCPC
}

A s of 2007, it was estimated that 240,000 Canadians were chronically infected with hepatitis $\mathrm{C}$ virus $(\mathrm{HCV})$, with higher rates in certain at-risk populations (1). It is possible that this figure underestimates the prevalence of HCV infection, and other estimates are significantly higher $(2,3)$. Unfortunately, firm data regarding national prevalence are lacking. What is clear is that the greatest risk for acute HCV infection is intravenous drug use, which accounts for nearly twothirds of new cases in Canada (1). Population-based studies on the incidence and prevalence of HCV infection in Canada are sparse. Despite this, there have been several studies that show higher rates of HCV infection in Aboriginal people; however, these studies have only examined high-risk groups within the Aboriginal community such as incarcerated persons and intravenous drug users.

In the current issue of the Canadian Journal of Gastroenterology, Uhanova et al (4) (pages 336-340) describe the incidence and prevalence of HCV infection in a Canadian First Nations population. This study is important in that it is the first population-based study to examine HCV infection in this group. The investigators used the Manitoba Health Plan Registry to identify 671 First Nations individuals in Manitoba who tested positive for HCV between 1991 and 2002. The majority of HCV-infected Aboriginal individuals lived in an urban setting despite the fact that most First Nations people were rural habitants. Uhanova et al confirmed previous studies that showed a higher prevalence of HCV in First Nations people compared with non-Aboriginals. Surprisingly, the authors show that more female than male aboriginals acquired $\mathrm{HCV}$ in that time period, a trend that is opposite to what has been reported in the non-Aboriginal population (4). It is also concerning that despite a decreasing incidence of HCV infection in the general Canadian population, this study shows that the rate of new HCV infections in the First Nations population is increasing (4).

There are, however, a few important limitations to this study. First, the authors did not describe the rate of spontaneous clearance of HCV, which has been shown to occur more frequently in Aboriginals, especially First Nations women (5). The prevalence of HCV in the First Nations population may, therefore, be overestimated due to an inability to ascertain who cleared HCV between 1991 and 1995. Along these same lines, it would be helpful to know the rate of HCV-HIV coinfection in this population because individuals coinfected with HIV are less likely to spontaneously clear HCV (5).

Furthermore, the authors did not categorize HCV infection according to genotype. Because HCV genotype has major implications on hepatitis $\mathrm{C}$ treatment and rates of clearance with treatment, it would be useful to know whether there are differences in the HCV genotypes acquired by Aboriginals compared with non-Aboriginals. Finally, the definition of First Nations in this study is limited by the definitions set out by the Manitoba Health insurance system, which, due to historical and political reasons, restricts who is eligible for registration as First Nations. As a result, patients who would selfidentify as First Nations may not have been included in this study, thereby potentially underestimating the overall burden of HCV infection in Aboriginal people. Future studies involving First Nations people are needed to help clarify these important epidemiological factors of HCV infection.
In the battle against $\mathrm{HCV}$, there is a palpable sense that we are starting to win. The recent introduction of the first-generation directacting antivirals, telaprevir and boceprevir, along with the promise of new therapies in the near future, offer the hope that we will soon be able to eradicate HCV. Added to this excitement is the apparently decreasing incidence rate of HCV infection in Canada (1). However, Uhanova et al (4) offer a sobering view of the work that needs to be done to reduce transmission and prevalence of HCV in the often disenfranchised First Nations population in which its incidence is rising.

Perhaps the most important question raised from the study by Uhanova et al is what lies beneath the surface of these results. Due to the methodology of the study, there is little extra demographic information available to help explain why the young urban First Nations women of Manitoba are at increased risk of acquiring HCV. The authors hypothesize that this may reflect an increased rate of intravenous drug use in this group. Based on previous studies, such as the Cedar Project (6), we can only assume that such high-risk behaviours are plausible explanations for this trend.

A sad indicator of the disenfranchised status of Canadian Aboriginals is that they are proportionally over-represented in populations living on the street as well as those who are incarcerated. Both of these populations are well known to have a significantly increased prevalence of $\mathrm{HCV}$ infection. This may account for many of the observations of the study by Uhanova et al. In that light, the high preponderance of urban versus rural $\mathrm{HCV}$-infected persons is predictable: street people are only found in urban centres.

Ultimately, management of HCV requires more than just the right medications - a greater understanding of the social context for why people acquire $\mathrm{HCV}$ is required. As a result, there is a need for improved multifaceted treatment strategies for patients with high-risk behaviours and poor social supports to enhance outcomes and control the spread of HCV. This study emphasizes the need for further research into marginalized populations with HCV infection.

\section{REFERENCES}

1. Remis RS. Modelling the Incidence and Prevalence of Hepatitis C Infection and its Sequelae in Canada, 2007 < phac-aspc.gc.ca> [cited 2013 May 2]. <www.phac-aspc.gc.ca/sti-its-surv-epi/model/ pdf/model07-eng.pdf> (Accessed May 2, 2013).

2. Cornberg M, Razavi HA, Alberti A, et al. A systematic review of hepatitis $\mathrm{C}$ virus epidemiology in Europe, Canada and Israel. Liver Int 2011;(31 Suppl 2):30-60.

3. Wong T, Lee SS. Hepatitis C: A review for primary care physicians. CMAJ 2006;174:649-59.

4. Uhanova J, Tate RB, Tataryn DJ, Minuk GY. The epidemiology of hepatitis $\mathrm{C}$ in a Canadian indigenous population. Can J Gastroenterol 2013;27:336-40.

5. Grebely J, Raffa JD, Lai C, et al. Factors associated with spontaneous clearance of hepatitis $\mathrm{C}$ virus among illicit drug users. Can J Gastroenterol 2007;21:447-51.

6. Cedar Project Partnership, Mehrabadi A, Paterson K, Pearce M, et al. Gender differences in HIV and hepatitis $\mathrm{C}$ related vulnerabilities among aboriginal young people who use street drugs in two Canadian cities. Women Health 2008;48:235-60.

Division of Gastroenterology and Hepatology, University of Calgary, Calgary, Alberta

Correspondence: Dr Samuel S Lee, Division of Gastroenterology and Hepatology, University of Calgary, 3330 Hospital Drive Northwest,

Calgary, Alberta T2N 4N1. E-mail samlee@ucalgary.ca

Received and accepted for publication May 7, 2013 


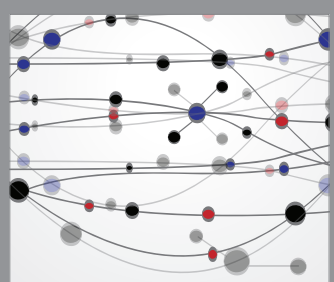

The Scientific World Journal
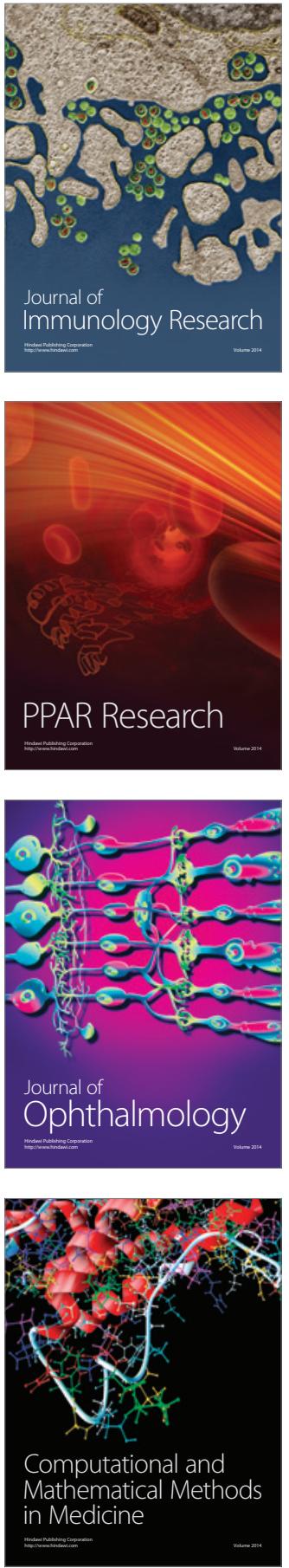

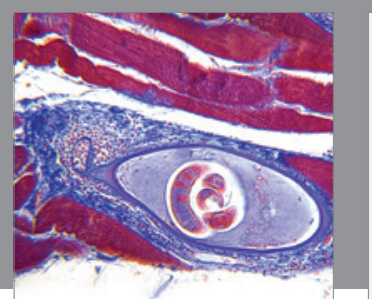

Gastroenterology Research and Practice

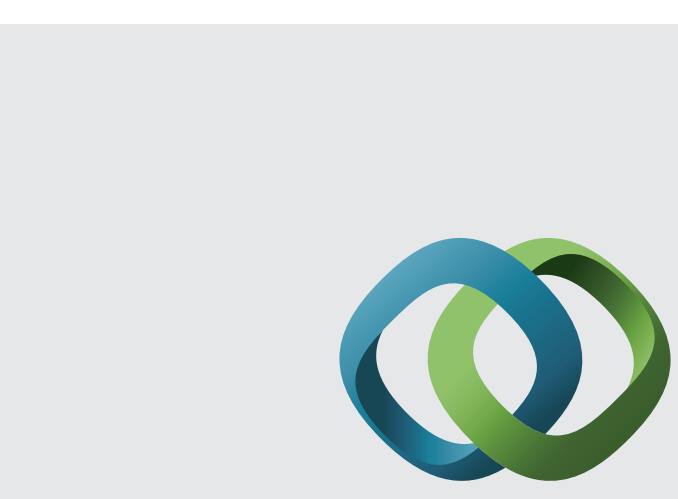

\section{Hindawi}

Submit your manuscripts at

http://www.hindawi.com
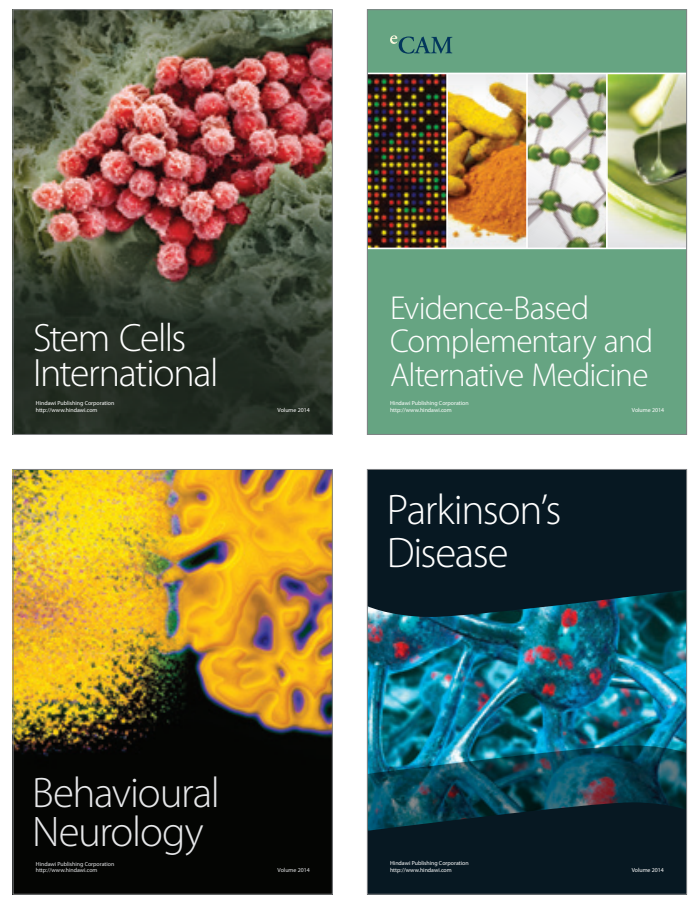
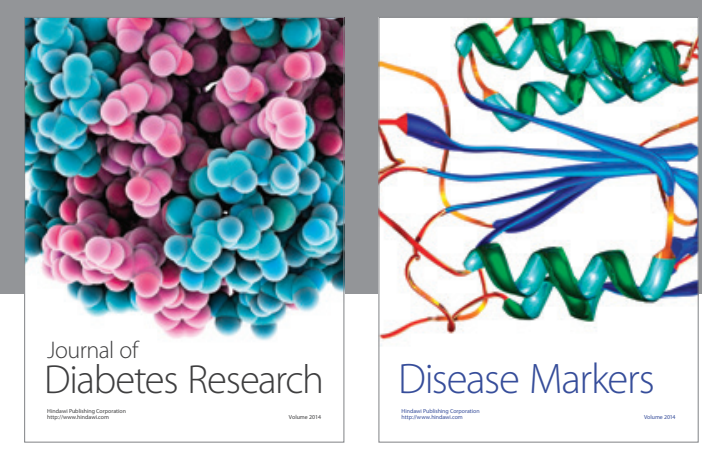

Disease Markers
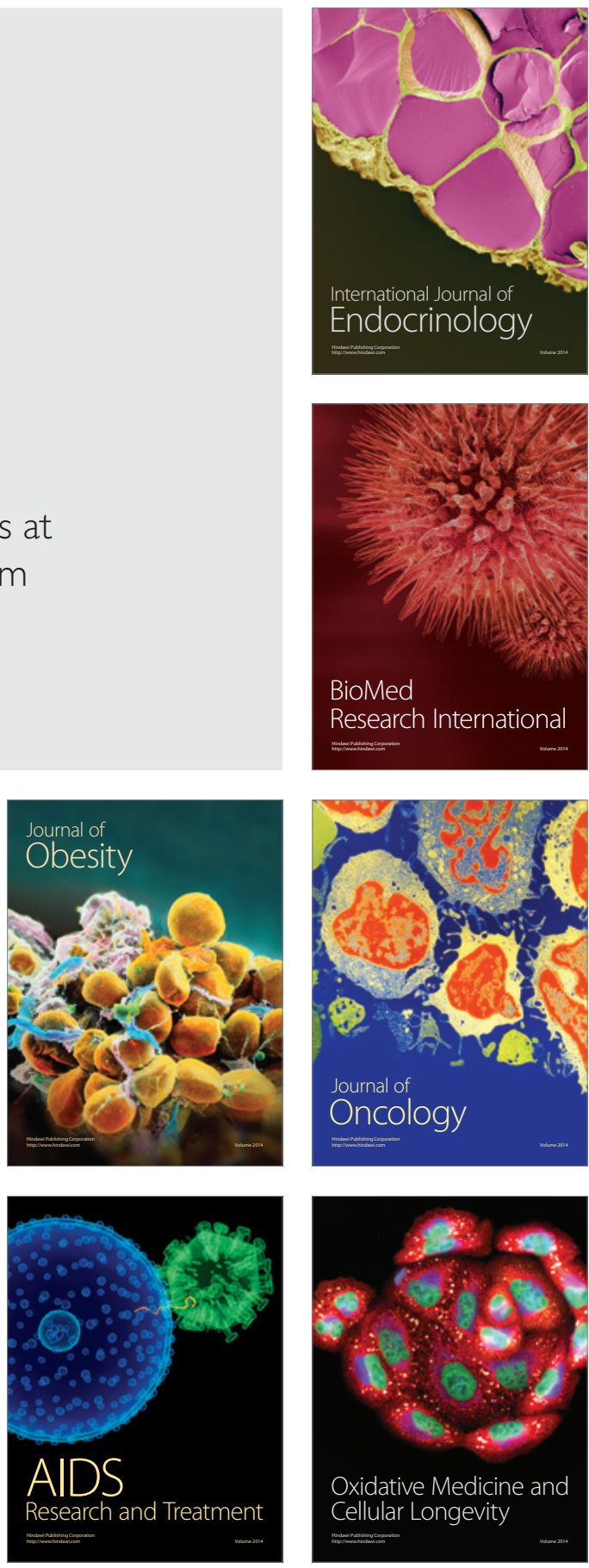